\title{
Goffredo Telles Junior em seu Jubileu de Cátedra.
}

\section{A Redação}

Completa 25 anos de exercício na cátedra de Introdução à Ciência do Direito, o insigne professor doutor Goffredo da Silva Telles Junior.

Após sua posse, prossegue numa ininterrupta série de publicaçōes jurídicas, conferências, discursos, aulas curriculares e extracurriculares; compöe numerosas Comissões Julgadoras de concursos, em todos os graus docentes e em várias especialidades, em São Paulo, no interior e em outros Estados. Participa da Administração pública, da Direção da Faculdade de Direito da Universidade de São Paulo, do Conselho Universitário da USP, de Congressos e Debates; dedica-se com pertinácia e extremo de cuidado à execução de programas docentes, administrativos e políticos.

Com visão de jurista filósofo, penetra no âmago dos problemas, propondo soluções, geralmente aceitas e aplicadas, pois cada aula, artigo ou livro, cada documento redigido, cada atitude política ou administrativa é aprofundado pela meditação e estudo contínuos, razão de suas inovações doutrinárias e liderança pessoal.

Desde o início da carreira, propugna a causa pública, da Justiça e do Ensino, como ideais de sua vida de professor de Direito. Por isso, jamais alheiou-se comodamente das crises em qualquer campo. Expõe aberta e destemidamente suas proposições, proclamando, sempre, os direitos do homem em bases democráticas, enfrentando, inclusive, ideologias governamentais opostas.

Daí sua extraordinária popularidade. Os jovens encontraram, sempre, no Professor Goffredo Telles Júnior o patrono certo, admirado e querido.

Sua vida está de tal forma ligada aos movimentos universitários e políticos da época que o registro dos fatos aqui, embora resumidos, além de constituir-se em homenagem aos 25 anos de cátedra de Sua Excelência, é contribuição para a história da Academia e para a história política do Brasil. 


\section{Notas Biográficas}

Goffredo da Silva Telles Junior nasceu na cidade de São Paulo, em 16 de maio de 1915. É filho de Goffredo Teixeira da Silva Telles, bacharel formado por esta Faculdade (Turma de 1910), poeta, membro da Academia Paulista de Letras, fazendeiro, Prefeito de São Paulo no ano da Revolução Constitucionalista de 1932, Presidente do Conselho Administrativo do Estado, de 1937 a 1945 e Presidente da Associação dos Antigos Alunos da Faculdade de Direito. Sua mãe é a Sra. Carolina Penteado da Silva Telles.

Foi seu avô paterno o Professor Augusto Carlos da Silva Telles, engenheiro, lente catedrático da Escola Politécnica de São Paulo. Sua avó paterna foi a Sra. Eugenia Teixeira Leite da Silva Telles, filha dos Barões de Vassouras.

Foi seu avồ materno o Sr. Ignacio Leite Penteado, fazendeiro e comissário de café em Santos. Foi sua avó materna a Sra. Olivia Guedes Penteado, filha dos Barões de Pirapitingui, dama que desempenhou papel relevante no desenvolvimento das artes no Brasil.

Casou-se, em primeiras núpcias, com Elza Xavier da Silva Telles, de quem teve um filho, chamado Goffredo, ambos falecidos.

Em segunda núpcias, casou-se com a escritora Lygia Fagundes Telles, de quem tem um filho, que também recebeu o nome de Goffredo.

Em setembro de 1967, casou-se com Maria Eugenia Raposo da Silva Telles, advogada militante, com quem tem uma filha, chamada Olivia.

Fez suas primeiras letras no "Cours Hattmer" de Paris. Em São Paulo, fez o curso primário e o primeiro ginasial no Liceu Franco Brasileiro (atual Ginásio Pasteur); e os outros quatro anos, no Ginásio São Bento.

Ainda Ginasiano, foi soldado voluntáric de São Paulo, na Revolução Constitucionalista de 1932.

Em 1933, matriculou-se na Faculdade de Direito de São Paulo, Largo de São Francisco.

No ano de 1934, inscreveu-se na Ordem dos Advogados do Brasil, como solicitador acadêmico.

Foi um dos fundadores da Associação Alvares de Azevedo, que lançou a revista Arcadia, famoso centro de debates, dentro da Faculdade. 


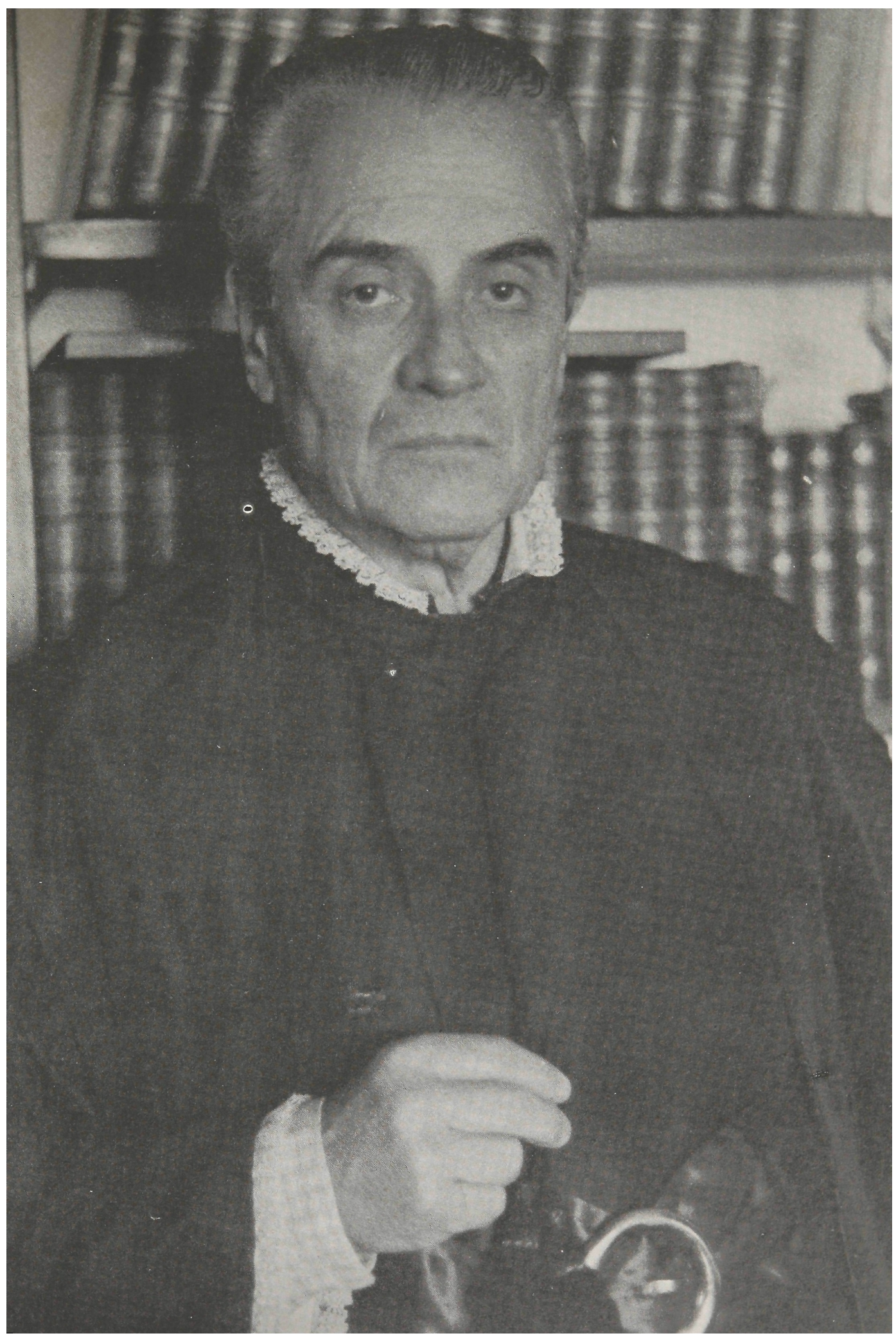


Pertenceu à Academia de Letras da Faculdade de Direito.

Formou-se na Turma de 1937, colando grau em janeiro de 1938. Tinha, nessa ocasião, 22 anos de idade.

Já havia iniciado sua vida política, mas, com a implantação do Estado Novo, interrompeu-a e dedicou-se à advocacia e aos estudos de Filosofia e de Direito.

Destacou-se como advogado de defesa no Tribunal do Júri de São Paulo.

\section{O Livre Docente}

O Professor Goffredo da Silva Telles começou a preparar-se para a carreira docente desde o $3 .^{\circ}$ ano do curso jurídico, isto é, desde 1935. Portanto ao terminá-lo, em 1937, já delineara seu caminho: tornar-se professor da Academia de São Francisco. E, dois anos após, submeteu-se a concurso para a cátedra de Direito Judiciário Penal.

Embora tivesse alcançado aprovação nas provas do concurso, não logrou aprovação final, por ter-lhe faltado nota suficiente de títulos, fato normal, tratando-se, na época, de um jovem de 24 anos. Saiu vencedor o Professor Canuto Mendes de Almeida, recentemente aposentado.

Nessa época, publicou seu primeiro livro, Justiça e Júri no Estado Moderno. Escrito numa fase histórica de extrema gravidade, em pleno apogeu do Nazismo, esse livro tem a virtude de revelar, de maneira inequívoca, o pensamento político de seu autor, em franca oposição a todas as formas totalitárias de Estado.

Não venceu seu primeiro concurso, mas saiu dele com experiência e preparo, que lhe valeram um contrato para as funções de Professor de Lógica do Colégio Universitário, no Curso Pré-Jurídico da Faculdade de Direito da Universidade de São Paulo.

Começou a lecionar em 6 de abril de 1940. Sua carreira de Professor da USP, dentro da Faculdade de Direito, teve início nesse dia.

Lecionou Lógica até 1944, quando foi extinto o Colégio Universitário.

Ainda no ano de 1940, inscreveu-se para o concurso à Livre Docência de Introdução à Ciência do Direito, na Faculdade de Direito da Universidade de São Paulo. 
O Catedrático da disciplina era o Professor Spencer Vampré. Com a tese $A$ Definição do Direito, foi aprovado e recebeu o título em 3 de abril de 1941, aos 25 anos de idade.

Iniciou então a atividade de Professor de Direito, que se desenvolveu intensamente, durante 39 anos, sem descurar a pesquisa e estudo de várias matérias, como Filosofia, Direito Penal e Processual Penal, Direito do Estado, Direito Internacional Público e outras, adquirindo, mais e mais, profunda e diferenciada cultura filosófico-jurídica.

Em setembro de 1941, pronunciou conferência sobre $O$ Júri no Brasil Moderno, no Instituto de Estudos Brasileiros, do Rio de Janeiro.

Representou, em julho de 1942, a classe dos advogados no $1 .^{\circ}$ Congresso Nacional do Ministério Público.

A Revista da Faculdade de Direito de 1942, publicou seu artigo "Concepção sintética do Direito", que é um apanhado do pensamento do Professor Spencer Vampré.

Em maio de 1943, foi admitido como membro efetivo do Instituto dos Advogados de São Paulo.

A contar do princípio do ano de 1944, regeu em diversos períodos, nos impedimentos do Professor Spencer Vampré, a Cadeira de que era Livre Docente. Substituiu também, freqüentemente, outros Professores da Faculdade de Direito. Em conseqüência, teve oportunidade de dar aulas sobre pontos de quase todas as disciplinas do Curso Jurídico.

Em 1944, regeu a Cadeira de Direito Internacional Público, por convocação do Catedrático, Professor Brás de Souza Arruda. Lecionou História Geral no Colégio do Estado.

Em outubro, desse mesmo ano, foi nomeado Conselheiro do Conselho Penitenciário do Estado. Nessa qualidade, mais tarde, em 1956, então já catedrático, redigiu o Regimento Interno do Conselho Penitenciário de São Paulo, que serviu de modelo para os Conselhos Penitenciários de muitos outros Estados.

Em 1945 e 1946, lecionou Direito Internacional Público e História das Doutrinas Políticas, na Faculdade de Ciências Econômicas, anexa à Escola de Comércio Alvares Penteado, no Largo de São Francisco.

Nessa época, foi eleito Deputado Federal Constituinte e ausentou-se da Faculdade para cumprir o mandato de Deputado, até 1950.

Em novembro de 1949, por motivo da passagem do primeiro centenário do nascimento de Ruy Barbosa, proferiu, pela 
Rádio Tupi e Rádio Tamoio do Rio de Janeiro, uma alocução sobre a personalidade de Ruy.

Nesse ano, publicou o Tratado da Conseqüência, que é um curso de Lógica Formal.

Terminado seu mandato, em 1950, recusou-se a pleitear nova eleição, e voltou para a Faculdade de Direito.

A convite do Centro Acadêmico XI de Agosto, ministrou, na Faculdade, durante o segundo semestre de 1952, um curso livre de extensão cultural, sobre a Gênese da Norma Jurídica.

Em 1951, pronunciou na Faculdade de Direito, sobre $O$ Divórcio, uma aula pública, que teve excepcional repercussão.

No encerramento do ano letivo de 1952, seus alunos primeiranistas lhe ofertaram uma placa de prata, em sinal de homenagem e agradecimento.

Em setembro de 1953, na Sociedade de Criminologia e Ciência Penitenciária, pronunciou conferência sobre o Processo de Reajustamento da Pena, na qual mostrou a necessidade da criação de uma Ação Especial Pública, a ser movida durante a execução da pena, para o fim de individualizá-la.

Ao fim deste ano letivo, foi alvo de expressiva homenagem de seus alunos do $1 .^{\circ}$ Ano, que lhe ofertaram um brinde de prata, com a efígie da Justiça.

\section{O Catedrático}

Desde $1 .^{\circ}$ de março de 1951 , vinha regendo, ininterruptamente, a cadeira de Introdução à Ciência do Direito, da qual o Professor Spencer Vampré estava afastado por motivos de saúde.

Em outubro de 1953, apresentando monografia em dois volumes, intitulada $A$ Criação do Direito, inscreveu-se entre os candidatos ao concurso para a conquista da cátedra de que era Livre Docente. Seus concorrentes foram os bacharéis Alberto Moniz da Rocha Barros, Bertho Antônio Condé, João Rodrigues de Meréje e Luiz Silveira Mello. A Comissão examinadora ficou constituída pelos Professores Doutores José Carlos de Ataliba Nogueira e Cândido Motta Filho, da Faculdade de Direito de São Paulo; Arnaldo Medeiros da Fonseca e Hélio Bastos Tornaghi, da Faculdade Nacional de Direito do Rio de Janeiro, e Darcy Azambuja, da Faculdade de Direito da Universidade de Porto Alegre. As provas realizaram-se entre 5 e 14 de junho de 1954. Foi aprovado com distinção, 
em primeiro lugar. O bacharel Alberto Moniz da Rocha Barros conquistou a Livre Docência.

Tomou posse de sua cadeira na data evocativa de 11 de agosto de 1954, em sessão solene, realizada no Salão Nobre da Faculdade de Direito, perante a Congregação e grande assistência, estando presentes os juristas estrangeiros que participavam, em São Paulo, do Congresso Internacional de Direito Social. Foi saudado pelo Professor Dr. Braz de Souza Arruda, então Diretor da Faculdade, e pelo Professor Dr. José Soares de Mello. Agradecendo, pronunciou, sem ler, um discurso sobre Spencer Vampré e sobre a missão do professor.

Como catedrático, continua a intensa e constante atividade iniciada na Livre Docência, exercendo ao mesmo tempo as múltiplas funções docentes, políticas e administrativas. Além das aulas curriculares nos diversos graus universitários, ministra aulas de abertura ou de encerramento de cursos universitários, cursos de extensão ou especiais, seminários, conferências, palestras, entrevistas em São Paulo, no interior e em outros Estados. Publica livros, ensaios, artigos, monografias e discursos pronunciados nas universidades paulistas ou de outros Estados. Participa da Administração da Faculdade de Direito, do Conselho Universitário; do Conselho Penitenciário do Estado e da Secretaria da Educação da Prefeitura. Participa constantemente de bancas examinadoras de concursos em vários graus docentes, de Congressos de Direito e de Debates. Tudo isto sem descurar seus estudos e pesquisas, que jamais abandonou.

Além de lecionar Introdução à Ciência do Direito no curso de bacharelado, regeu, no antigo curso de Especialização, a nível de pós-graduação, a cadeira de História das Doutrinas Políticas, por designação unânime da Congregação. No mesmo curso, lecionou Sociologia Jurídica e Método das Ciências Políticas.

Por força do Art. 100 da Constituição de 24 de janeiro de 1967, foi declarado estável no cargo de Professor do Curso de Especialização, cujas funções vinha exercendo, como Professor Catedrático contratado, desde 1961.

Em 22 de outubro de 1969, entrou em Regime de Dedicação Integral à Docência e à Pesquisa. Observe-se que a adoção oficial desse regime representou, simplesmente, a passagem de um estado de fato para um estado de direito, porque, em verdade, já havia quase vinte anos que o Professor Goffredo dedicava à docência e à pesquisa, mais de cinqüenta horas semanais. 
Em 1955 fundou e fez funcionar, na Faculdade de Direito, um Seminário de Ética e Ciências Humanas, onde se realizaram cursos intensivos de Filosofia da História, de Ética e de Teoria do Estado.

Mais tarde, esse seminário transformou-se no Seminário de Introdução à Ciência do Direito, que passou a funcionar no período da tarde, e que perdura, com sucesso, até a presente data.

Ainda em 1955, sob os auspícios da Sociedade Brasileira de Criminologia e Ciência Penitenciária, pronunciou uma conferência sobre o Problema da Prostituição.

No número de 1956, a Revista da Faculdade de Direito publicou um artigo seu, intitulado Conhece-te a ti mesmo.

No fim do ano, foi eleito patrono da turma de bachalandos de 1956.

Foi paraninfo da turma de 1957 dos Aspirantes a Oficiais da Reserva (C.P.O.R.), sendo patrono o Senhor Presidente da República, Marechal Eurico Gaspar Dutra.

Em novembro, participou do Congresso Nacional de Filosofia, realizado em São Paulo, tendo apresentado dois trabalhos: $O M O I$ e o JE e Nota à margem da Dialetica do Conhecimento, ambos publicados nos Anais do Congresso e em separatas.

Em maio de 1960 pronunciou conferência intitulada Reflexões sobre a ordem $e$ a desordem, no Palácio da Justiça, na Sala do Conselho Superior da Magistratura, a título de preparação para a Páscoa da Família Forense.

Aos 10 de junho, pronunciou conferência na Casa de Portugal, sobre a Atualidade de Camões. Esta conferência lhe valeu a comenda da "Ordem do Mérito Infante Dom Henrique".

No dia da Independência, proferiu uma alocução, $O$ Sete de Setembro e o Destino Nacional, na Associação dos Cavaleiros de São Paulo e no Ateneu Paulista de História.

Ainda em setembro de 1960, pronunciou uma conferência sobre $O$ Infante D. Henrique e a mensagem histórica de Portugal, no auditório da Bibioteca Municipal, sob os auspícios da Secretaria de Educação e Cultura da Municipalidade.

Em dezembro, no Real Gabinete Português de Leitura, do Rio de Janeiro, repetiu essa conferência recebendo nessa ocasião, o Diploma de Sócio Honorário do referido Gabinete.

Em abril de 1966, repetiu, na Sala do Estudante da Faculdade de Direito, sua conferência sobre O Processo de Reajustamento da Pena. 
A 27 de maio, no Tribunal de Alçada, pronunciou uma conferência subordinada ao tema Reflexões sobre a Inteligência Humana, em preparação para a Páscoa da Família Forense do Brasil.

Ainda em 1961, deu a lume a sua Dissertação sobre o Universo, publicada na "Revista da Faculdade de Direito" de 1960.

No encerramento deste ano letivo, seus alunos o homenagearam, com a oferta de uma estatueta da Justiça.

Ao fim do ano seguinte, em novembro de 1962, seus alunos tornaram a homenageá-lo, oferecendo-lhe uma placa de prata.

Em 1964, pronunciou, sem ler, em nome da Congregação dos Professores da Faculdade, no Salão Nobre, dois discursos famosos, ambos de homenagem póstuma: o primeiro, ao Professor Braz de Souza Arruda; e o segundo, ao Professor Spencer Vampré.

Foi paraninfo dos bacharelandos de 1964, Turma Spencer Vampré, da Faculdade de Direito da USP.

Durante o ano de 1965, publicou dois livros, um em cada uma de suas especialidades: sobre Filosofia, o primeiro tomo da Filosofia do Direito; sobre Teoria do Estado, A Democracia $e$ o Brasil. O segundo tomo da Filosofia do Direito foi publicado em 1967.

Em março de 1968, falou em nome da Assembléia Universitária dạ Universidade de São Paulo, saudando o Professor Ernst Heinitz, da Universidade Livre de Berlim, na solenidade em que o título de Doutor Honoris Causa foi conferido ao eminente jurisconsulto alemão.

A "Revista de Direito Público" de São Paulo, em seu Volume 4, relativo a abril e junho de 1968, publicou seu trabalho sobre "Discriminação constitucional das fontes de receita tributária".

Durante o ano de 1968, pronunciou diversas conferências, entre as quais se destacam as seguintes: " $A$ Cultura $e$ os Tempos Novos", na Associação de Estudos Clássicos do Brasil; "A Sublevação do Mundo e o Pássaro Azul", na Academia Paulista de Letras; "Evolução e Revolução", no Centro Acadêmico 22 de Agosto, da Faculdade de Direito da Pontifícia Universidade Católica; "Direito, Desenvolvimento e Reforma Universitária", na Faculdade de Direito de Presidente Prudente, a convite do Diretório Acadêmico Castro Alves.

Em junho de 1969, pronunciou, na Faculdade de Direito de Guarulhos, uma conferência sobre o Processo de Individua- 
lização e Reajustamento da Pena, na qual voltou a demonstrar a necessidade da criação de uma Ação Especial Pública, a ser movida durante a execução da pena, para o fim de individualizá-la.

Em Sessão Magna, realizada a 11 de agosto de 1969, pronunciou a Aula Inaugural da Faculdade de Direito de Itú.

No fascículo 80 da "Revista Brasileira de Filosofia", relativo ao último trimestre de 1970 , publicou um artigo inovador, "O Direito Quantico".

Por ofício de 5 de março de 1971, o Diretor do Instituto de Física da USP, Prof. José Goldenberg, o convidou a pronunciar conferência sobre o Direito Quantico, em um dos seminários do referido Instituto.

Em setembro de 1971, publicou seu livro "O Direito Quantico", pela Editora Max Limonad. A edição de dois mil volumes se esgotou em poucos dias. Em fins do mesmo mês, a editora lançou a $2 .^{a}$ edição

Em novembro, pronunciou conferência na Faculdade de Direito de São José dos Campos, abrindo o ciclo "Brasil-Jurídico, 1971", sobre o tema "Fundamento, evolução e involução das ordenações sociais", tendo sido alvo de expressiva homenagem.

Em maio, ingressou na Sociedade Brasileira para o Progresso da Ciência.

Por carta de 19 de maio de 1972, assinada pelo Prof. Simão Mathias, Secretário Geral dessa Sociedade, foi convidado para integrar o Conselho Editorial da revista "Ciência e Cultura", órgão da mesma Sociedade.

Em julho de 1972, foi eleito Membro Titular da Acadêmia Paulista de Direito.

Em 12 de outubro, a Congregação o elegeu para membro da Comissão de Ensino da Faculdade de Direito, da qual ficou Presidente.

Sob o patrocínio da Academia Paulista de Direito, deu um curso intensivo de 5 dias sobre $A$ Lógica do Jurista, em fevereiro de 1973. Em abril desse mesmo ano, no ciclo de conferências sobre a Estudo do Direito, promovido pela mesma Academia, proferiu conferência sobre o Curso de Pós-Graduação, assunto muito cuidado pelo professor, desde 1968, que chegou a elaborar normas práticas para seu funcionamento, transformadas em portaria em 1973. 
Em 25 de março, também na Academia Paulista de Direito, pronunciou conferência sobre o tema "Violência e responsabilidade, à luz da ciência de nossos dias".

Em 9 de maio de 1973, no Instituto Brasileiro de Filosofia, proferiu conferência intitulada "As lições da Biologia sobre a liberdade humana".

Em setembro, publicou novo artigo sobre "O Direito Quantico", na Revista da Faculdade de Direito, Vol. LXVIII (1. ${ }^{\circ}$ fascículo, Ano 1973).

Em 28 de março de 1975, 6. ${ }^{a}$ Feira da Paixão, proferiu, pela Rádio Jovem Pan, uma alocução de cinqüenta minutos, sobre as duas questões seguintes: "Existem seres vivos em outros planetas?", "Como explicar o milagre, dentro da ordem cosmica?".

Na Universidade Mackenzie, deu uma aula sobre a Nova Lógica na Interpretação do Direito Civil, em curso de extensão promovido pela Academia de Letras daquela Universidade, em 1976.

A convite dos coordenadores dos cursos de Problemas Brasileiros ministrados a nível de Pós-Graduação na Faculdade de Direito da Universidade de São Paulo em 1974, 1975 e 1976, abordou temas jurídico-filosóficos e políticos, como os seguintes: $O$ Legal e o Legítimo no Processo Legislativo Brasileiro, O Fundamento Genético e Celular do Comportamento dos Seres em Geral e do Homem em Particular e Roteiros da Democracia no Brasil.

No ITA, em outubro de 1974 inaugurou o curso com o tema: Moral, Ordem e Civismo, Segundo as Últimas Descobertas da Biologia.

$\mathrm{Na}$ Escola de Comunicação e Artes da USP, em 1976, repetiu o tema $O$ Legal e o Legítimo no Processo Legislativo Brasileiro.

Em 1976, no curso de Extensão de Introdução ao Estudo do Direito, na Faculdade de Direito da Universidade de São Paulo, proferiu a aula de encerramento sobre o tema Desenvolvimento da Política Brasileira no Século XX.

No Seminário sobre o Pensamento Jurídico e o Ensino do Direito no Brasil, em agosto de 1975, promovido na Faculdade de Direito de Minas Gerais e pelo Conselho de Extensão Cultural da Mesma Universidade, proferiu conferência sobre a Influência da Teoria Liberal Democrática e de outras 
Teorias no Direito Constitucional Brasileiro e uma sugestão Realista para o Futuro.

Em outubro de 1976 participou do painel de debates sobre os Problemas Carcerários de São Paulo, organizado pelo Diretório Acadêmico 22 de Agosto, da Faculdade de Direito da Pontifícia Universidade Católica de São Paulo.

Em 16 de abril de 1976, 6. ${ }^{\text {a }}$ Feira da Paixão, proferiu, pela Jovem Pan, uma alocução de sessenta minutos, sobre a seguinte questão: "Para onde caminha a humanidade?".

Em agosto, deu uma aula sobre a "Nova lógica na interpretação do Direito Civil", num curso de extensão, promovido pela Academia de Letras da Universidade Mackenzie.

Em novembro, no Salão Nobre da Faculdade de Direito, perante grande assistência, fez uma dissertação sobre " $A$ nova lógica na interpretação do contrato de trabalho", em Curso Interdepartamental, organizado pelo Departamento do Direito do Trabalho.

No correr do último trimestre de 1976, entregou à Saraiva S.A., Livreiros Editores, seus originais sobre os verbetes Absoluto, Autoridade, Autorização, Autorizante e Autorizar, num total de 92 páginas datilografadas, para a Enciclopédia Saraiva do Direito.

Os bacharelandos de 1977 o elegeram Patrono da Turma e, na festa de formatura, em 8 de dezembro, prestaram-lhe homenagem especial, ofertando-lhe uma placa de prata comemorativa.

Na Revista da Faculdade de Direito, Vol. LXXII, $10^{\circ}$ fascículo do ano de 1977, publicou longo artigo, intitulado "Revisão dos conceitos de autoridade, autorização, permissão, Direito Subjetivo e Norma Jurídica".

Durante o ano de 1978, sua colaboração para a Enciclopédia Saraiva do Direito foi grande. Entregou à editora seus originais sobre os verbetes Coação, Coatividade, Direito Subjetivo, Norma Juridica e Lei (Teoria da Lei), num total de 111 páginas datilografadas. Sobre seu trabalho sobre o Direito Subjetivo, o Coordenador da Enciclopédia, Professor Limongi França, disse, em carta, que aquela colaboração era "o melhor texto sobre o assunto, até hoje escrito".

Em agosto de 1978, a convite do coordenador do Curso de Problemas Brasileiros, na Pontifícia Universidade Católica de São Paulo, proferiu duas palestras sobre o tema Política Moderna Brasileira: 1930 a 1964. 
Na XXI Semana de Estudos Jurídicos Dr. Milton Duarte Segurado, em outubro de 1978, proferiu conferência na Faculdade de Direito da Pontifícia Universidade Católica de Campinas sobre Liberdades Democráticas, tendo sido homenageado, na ocasião, com placa de prata.

Desde 1956 até hoje, além dos estudos, aulas, conferências, entrevistas, congressos, debates, S. Excelência é constantemente convidado para compor bancas examinadoras, não somente em Faculdades de São Paulo, mas nas de outros Estados tais como Minas Gerais, Amazonas, Bahia. São concursos em todos os graus docentes, de várias disciplinas como Filosofia do Direito, Introdução à Ciência do Direito, Direito Penal, Direito Internacional Privado, Teoria Geral do Estado, o que dimensiona a cultura do Professor Goffredo Telles Junior.

Seus incontáveis examinandos são, hoje, quase todos, ilustres universitários ou políticos espalhados pelo Brasil a fora.

Os bacharelandos de 1978, da Faculdade de Direito da USP, deram seu nome à turma desse ano.

Na data evocativa de 11 de agosto de 1979, celebrou seu Jubileu de Cátedra.

Ao chegar ao $25 .^{\circ}$ aniversário de Catedrático, em 1979, o Prof. Goffredo completou 39 anos e 4 meses de docência na Universidade de São Paulo e na Faculdade de Direito do Largo de São Francisco.

\section{o Administrador}

A operosidade, cultura e dinamismo do Professor Goffredo Telles Junior levaram-no a participar da Administração da Faculdade de Direito da Universidade de São Paulo, em vários setores.

Em dezembro de 1957, foi eleito pela Congregação para o antigo Conselho Técnico-Administrativo da Faculdade de Direito, tendo tomado posse em 21 de janeiro de 1958, no qual permaneceu dez anos. Em julho de 1966, foi eleito Vice-Diretor, exercendo a Diretoria em duas ocasiões, durante os anos de 1967 e 1968.

Três fatos principais marcaram sua passagem pela Diretoria da Faculdade. O primeiro foi a adoção de novas medidas no concurso de habilitação de 1968 (Exames Vestibulares), em razão das quais tal Concurso foi considerado "o mais perfeito havido até aqui" (Carta do Centro Acadêmico XI de Agosto ao Diretor) 
O segundo foi a profunda e irreversível campanha moralizadora, levada a cabo em todos os setores da Secretaria da Faculdade. O terceiro, finalmente, foi a manutenção da mais completa ordem na Faculdade de Direito, com perfeito entendimento entre os alunos e a Diretoria, durante todos os meses de sua gestão, época que se caracterizou, em outras Faculdades da Universidade de São Paulo, pela violenta sublevação dos estudantes.

Enfronhado, pois, nos problemas universitários, propugnou a reforma universitária para a USP, tendo feito parte da Comissão de Estudos para sua implantação na Faculdade de Direito, o que se deu oficialmente aos 30 de agosto de 1971.

Em 25 de março de 1969 foi eleito por unanimidade Presidente da Associação Paulista dos Professores do Ensino Superior (APPES), entidade criada por inspiração do Professor Alberto Moniz da Rocha Barros, e que congregava professores de todo o Estado de São Paulo. Essa entidade tinha por fim o aperfeiçoamento do ensino superior, o relacionamento construtivo entre os estudantes e professores, e a defesa dos interesses morais e materiais do professorado superior.

Exonerou-se da Vice-Diretoria da Faculdade de Direito em maio de 1969, e desligou-se da Comissão de Pós-Graduação.

Indicado pela Congregação, passou a integrar o Conselho Universitário da USP, como representante da Faculdade de Direito.

Em 1970, após a Reforma Universitária e com a criação dos Departamentos, foi eleito Chefe do Conselho Departamental do Departamento de Filosofia e Teoria Geral do Direito da Universidade de São Paulo.

Consagrou-se a seu Departamento. Elaborou o projeto de Regimento dos Seminários e o projeto de Regulamento dos Cursos de mestrado e doutorado.

Manteve em funcionamento, com freqüência obrigatória e comprovada eficiência o Seminário vespertino de Introdução à Ciência do Direito.

Com a reforma universitária, o antigo Conselho Técnico Administrativo transformou-se em Conselho Interdepartamental, congregando os Chefes dos diversos departamentos, do qual o Professor Goffredo também fez parte, desde setembro de 1971 até agosto de 1973. 
Em 1970, elaborou o projeto de regulamento dos Cursos de Mestrado e Doutorado, que constituiriam a Pós-Graduação dos Cursos Jurídicos.

Em outubro de 1971, a Congregação dos Professores reconduziu-o, por aclamação, à Comissão de Pós-Graduação. E nessa qualidade, apresentou um rol de normas práticas para o funcionamento dos cursos de Pós-Graduação, Mestrado e Doutorado, convertido em portaria algum tempo depois.

Eleito, em 1972, presidente da Comissão e Coordenador dos Cursos, organizou com rigor, em maio de 1973, os cursos de Pós-Graduação da Faculdade de Direito.

Ainda em 1972, o Conselho de Ensino, Pesquisa e Extensão de Serviços à Comunidade (CEPE), órgão do Conselho Universitário, elegeu o infatigável professor membro da Câmara de Pós-Graduação. Foi eleito, naquele mesmo ano, membro da Comissão de Legislação e Recursos, cargo para o qual foi reeleito nos dois anos subseqüentes, com maioria absoluta de votos.

Em 1973, entregou ao Reitor da USP seu parecer sobre as formas de ingresso na carreira docente da Universidade e sobre a situação funcional dos Professores Livre-Docentes e Assistentes Contratados.

Além da intensa participação na Administração da Faculdade de Direito e outros órgãos universitários, anteriormente referidos, Goffredo Telles Junior participou também da Administração Pública.

Em outubro de 1944, foi nomeado Conselheiro do Conselho Penitenciário do Estado e, em 1955, redigiu seu Regimento Interno que serviu de modelo para Conselhos Penitenciários de outros Estados. Permaneceu nesse Conselho durante trinta anos.

Tendo sido nomeado Secretário da Educação e Cultura da Prefeitura de São Paulo, em 12 de abril de 1957, teve oportunidade de representar o Governo do Município de São Paulo nas solenidades do centenário da cidade de Caruarú, em Pernambuco, em maio daquele ano.

$\mathrm{Na}$ ocasião, em Recife, pronunciou conferência na Faculdade de Direito, expondo novamente suas idéias sobre a Repre. sentação Nacional e a Democracia, o que se repetiu em outras conferências proferidas, em junho, na cidade de Ribeirão Preto e em setembro em Jundiaí, ainda como Secretário da Educação. 
À frente da Secretaria da Educação do Município de São Paulo, S. Excelência lutou contra a extinção do Ensino Primário Municipal, e em julho apresentou ao Prefeito de São Paulo plano para a melhoria desse ensino.

Além disso, incrementou a vida artística musical da cidade, promovendo um grande Concurso Internacional de Piano, em agosto. No mesmo mês, realizou a célebre Semana Vila Lobos que constou de concertos e conferências. Após vencer resistências de toda ordem, trouxe a São Paulo o célebre compositor russo Aram Khachaturian, que regeu alguns concertos nesta cidade.

Ao mesmo tempo em que exercia o cargo de Secretário da Educação, continuava suas atividades docentes, tendo sido, inclusive, nomeado membro do Conselho Técnico Administrativo da Faculdade, tomando posse do cargo em 21 de janeiro de 1958.

Não recusou sequer o convite da turma de 1957 dos Aspirantes da Reserva (CPOR), para seu paraninfo, sendo patrono o Senhor Presidente da República, Marechal Eurico Gaspar Dutra. E nem o convite dos formandos de 1957 do Ginásio Perdizes, tendo sido homenageado com placa de prata.

Sobrecarregado, porém, de afazeres universitários, Sua Excelência optou pelos primeiros e pelos estudos. Exonerou-se da Secretaria da Educação para dedicar-se com mais afinco à elaboração de suas teorias sobre o conhecimento humano, a liberdade e a democracia, temas de livros futuros.

\section{O Político}

Goffredo Telles Junior iniciou sua vida política ainda estudante. Durante todo seu curso na tradicional Academia, participou ativamente da política nacional e estadual. Empenhou-se em campanhas memoráveis, na defesa de um ideário definido. Combateu, com igual intensidade, o comunismo, o fascismo e o liberalismo burguês. Lutou em nome de princípios espiritualistas, nacionalistas, anticapitalistas. Preconizou novas formas de representação popular, levado pelo pensamento de uma democracia para o Brasil.

Com dezoito anos de idade, ainda estudante, foi eleito, em 1934, suplente de deputado à Assembléia Constituinte do Estado de São Paulo. Pertencia, nesse tempo, à ala antifascista da Ação Integralista Brasileira. 
Quando ainda cursava o último ano da Faculdade, o Parlamento Nacional e as Assembléias Legislativas Estaduais foram fechadas, por ato do Presidente da República. Um decreto extinguiu todos os partidos políticos. E Getúlio Vargas implantou no País o chamado Estado Novo.

Nessa conjuntura, interrompeu sua atividade política para dedicar-se à profissão e aos estudos de Filosofia e de Direito. Mas, em dezembro de 1945, foi eleito Deputado Federal Constituinte. Obteve em número de sufrágios a $2{ }^{a}$ votação do País.

Na Assembléia Constituinte Nacional e na Câmara dos Deputados, manteve-se em atividade constante. Foi o primeiro deputado a dar resposta frontal aos discursos da bancada comunista. Lutou contra o fechamento do Partido Comunista. Combateu e obteve a retirada da emenda totalitária n. ${ }^{\circ} 3.159$, que deturparia por completo o sentido democrático da Constituição. Batalhou pela implantação de um sistema racional de discriminação de rendas, tendo escrito, sobre o assunto, um longo trabalho intitulado O Sistema Brasileiro de Discriminação de Rendas, que figura nos Anais da Constituinte e que saiu publicado em separata. Defendeu ardorosamente a causa municipalista. Tratou demoradamente dos problemas nacionais do algodão, do fio de seda, da brucelose. Combateu, com veemência, o primitivo tratado sobre o Instituto Internacional da Hiléia Amazônica, que depois foi alterado $e$ arquivado. Alertou a opinião pública sobre os abusos que estavam sendo praticados com os minérios preciosos e as areias monazíticas do Brasil. Apresentou projeto mandando incorporar os abonos aos salários dos trabalhadores. Apresentou um substitutivo, com longa justificação, ao projeto que reorganizava a Polícia Militar.

Terminado seu mandato em 1950, recusou-se a pleitear nova eleição e voltou para a Faculdade de Direito; mas não deixou de manifestar em todas as oportunidades sua vocação política, expondo abertamente, através de artigos, entrevistas ou conferências, o conceito de verdadeira democracia e demais idéias políticas, amadurecidas, então, pela experiência, meditação e estudo.

Em 1955, publicou no jornal "O Estado de São Paulo", três longos artigos sobre o tema Resistência Violenta aos Governos Injustos. Este trabalho foi reproduzido em muitas revistas especializadas no País, e, também na Revista da Faculdade de Direito, de 1955, da qual foram tiradas separatas. 
Em 9 de agosto de 1955, pronunciou conferência sobre Cultura e Revolução, na Sala do Estudante, a convite do Centro Acadêmico XI de Agosto, durante a Semana da Tradição, e na qual reprovou os "golpes de Estado", praticados somente para substituir homens por homens, e convocou a mocidade para a Renovação Ideológica de que o Brasil necessitava, isto é, para um grande movimento de Ressurreição Nacional, em nome de uma cultura política atualizada.

Em 1956 proferiu a Aula Magna de abertura dos cursos na Faculdade de Direito, versando o tema As Fontes do Direito e a Representação Política. Nessa oportunidade, propôs, diante da Congregação da Faculdade e de grande assistência, processos novos para tornar verdadeira a representação nacional e dar autenticidade ao regime democrático. As idéias expostas foram consubstanciadas no seu trabalho Lineamentos de uma Constituição Realista para o Brasil, publicado na Revista da Faculdade de Direito, em 1959, e em separatas.

Quando Secretário da Educação do Município de São Paulo, nas solenidades do centenário da cidade de Caruaru, em Pernambuco, representou o Governo Municipal de São Paulo e proferiu conferência na Faculdade de Direito do Recife expondo suas idéias sobre a Representação Nacional e Democracia. Ainda Secretário da Educação de São Paulo pronuncriou conferência em Ribeirão Preto, em junho de 1956, e em setembro de 1957, na cidade de Jundiaí, abordando o mesmo tema.

Desligado da Secretaria da Educação, em 1959, proferiu nova conferência no Fórum Roberto Simonsen, em que delineou as bases de uma Democracia Autêntica para o Brasil. Em outubro desse mesmo ano, "A Gazeta" publicou longa entrevista sua, sobre a necessidade de mudanças no regime constitucional brasileiro e, finalmente, em 1959, elabora e publica no volume LIV - f. II desta Revista, o seu Projeto de Constituição, sob o título Lineamentos de Uma Constituição Realista para o Brasil. Esse mesmo tema foi exposto mais tarde, em janeiro de 1963, no Congresso para a Definição das Reformas de Base, realizado em São Paulo.

Nesse mesmo ano, em agosto, na sessão solene organizada pelo Centro Acadêmico XI de Agosto, diante de uma assistência que superlotou o Salão Nobre da Faculdade, tornou a expor o tema, que despertava sempre grande entusiasmo político entre estudantes e o povo. 
Promovida pelo Centro Acadêmico João Mendes Júnior do Instituto Mackenzie, pronunciou conferência em 6 de maio de 1960, sobre Os Mitos da Constituição e as Bases de Uma Democracia Autêntica; e, em setembro, aborda novamente tema político na Associação dos Cavaleiros de São Paulo e no Ateneu Paulista de História, proferindo conferência sobre $O$ Sete de Setembro e o Destino Nacional.

Em 1965, publica o livro A Democracia e o Brasil.

Em março de 1966, sugeriu que o Instituto dos Advogados de São Paulo apresentasse, ao Governo Federal (Presidente Castelo Branco), um projeto de Constituição para o Brasil. Em 6 de maio o Instituto realizou reunião plena, na Faculdade de Direito da Universidade de São Paulo, e constituiu, para elaborar o projeto mencionado, uma Comissão de especialistas, da qual foi designado Coordenador. Após longo trabalho, a Comissão, em fins de setembro, apresentou ao Plenário do Instituto, um Projeto de Constituição, que foi aprovado e, depois, encaminhado ao Governo da República.

Em 21 e 28 de agosto e em 4 de setembro, publicou, no O Estado de São Paulo, uma série de artigos, sob o título geral: Por uma Nova Constituição.

Durante o ano de 1968, então Vice-Diretor da Faculdade de Direito da Universidade de São Paulo, pronunciou diversas conferências e como não podia deixar de ser, todas eivadas de idéias fiosóficas e políticas. Uma delas, proferida no Centro Acadêmico 22 de Agosto da Faculdade de Direito da Pontifícia Universidade Católica, versou o tema Evolução e Revolução. Tendo sido, então, taxado de subversivo fez um pronunciamento solene na Congregação dos Professores da Faculdade, em 13 de fevereiro de 1969, no qual, mais uma vez, definiu suas convicções filosóficas e políticas. Logo após, em março, pronunciou na Faculdade de Direito de Bragança Paulista uma conferência intitulada $O$ Poder Legislativo. De abril a junho, publicou na Folha de São Paulo uma série de 12 artigos sobre o Poder Legislativo e outros problemas Constitucionais.

Em 1970, quando já se exonerara da Vice-Diretoria da Faculdade de Direito da Universidade de São Paulo, apresentou, a pedido de amigos nas Forças Armadas, em setembro de 1970, ao Presidente da República, General Emílio Garrastazu Médici, um longo trabalho sobre um novo sistema de representação nacional.

No Diário de São Paulo de 26 de novembro e de 3 e 10 de dezembro, publicou três artigos, sob o título Um Poder 
Legislativo Autêntico, nos quais expôs as idéias contidas no trabalho entregue ao Presidente da República.

Em 26 de agosto de 1975, proferiu, em Belo Horizonte, uma conferência sobre $A$ Influência da Teoria Liberal Democrática e de outras Teorias no Direito Constitucional Brasileiro, e uma Sugestão Realista para o Futuro, no Seminário sobre O Pensamento Jurídico e o Ensino do Direito no Brasil, promovido pela Faculdade de Direito da Universidade de Minas Gerais e pelo Conselho de Extensão Cultural da mesma Universidade.

Em dezembro de 1976 ministrou duas aulas em cursos diferentes sobre Política. A $1 .^{\mathrm{a}}$ a convite do coordenador do Curso de Problemas Brasileiros, na Pós-Graduação da Faculdade de Direito da Universidade de São Paulo, sobre os Roteiros da Democracia no Brasil; a 2. ${ }^{\text {a }}$ no Curso de Extensão de Introdução ao Estudo de Direito, na Faculdade de Direito da Universidade de São Paulo, para encerramento, discorreu sobre o Desenvolvimento da Política Brasileira no Século XX.

De 1976 a 1977, preparava-se a Faculdade para as comemorações do sesquicentenário de fundação dos Cursos Jurídicos no Brasil, congraçando no mesmo entusiasmo cívico e cultural professores, alunos, funcionários da FADUSP e juristas de todo o Brasil. Sucediam-se os festejos, concertos, exposições, documentários, palestras, conferências e o Professor Goffredo fazia parte da Comissão Organizadora.

Na noite de 28 de abril, perante grande concentração de estudantes e do povo, no Largo de São Francisco, diante da Faculdade de Direito, proferiu, da Tribuna Livre, veemente discurso de repulsa aos Atos Institucionais da Revolução de 1964 e às emendas à Constituição, e de conclamação para a imediata instauração do Estado de Direito no Brasil.

No dia seguinte, abordou o mesmo tema, numa conferência proferida na Faculdade de Direito de Bauru, sobre O Legal e o Legítimo, no Direito de Nossos Dias.

Nesse mês de abril, o Jornal do Brasil, edições de 22, 23 e 24, publicou entrevistas suas sobre a necessidade de se extinguir o regime de exceção e de instaurar-se a democracia no Brasil. E a 11 de maio, o semanário de Samuel Wainer, Aqui São Paulo, publicou longa entrevista sua, sobre O que os Estudantes Querem, e sobre o despertar da consciência nacional para a Democracia.

Influenciado pelas constantes manifestações do Professor a respeito da democracia e incitações para implantá-la no Brasil, 
foi procurá-lo, em princípios de maio, um grupo de advogados e políticos, todos seus antigos alunos. Expuseram-lhe o propósito de comemorar a passagem do centésimo qüinquagésimo aniversário da fundação dos Cursos Jurídicos no Brasil, a se verificar em 11 de agosto, com o lançamento de um documento solene, que fosse uma vibrante Proclamação de Princípios, em sinal de repúdio pelo regime reinante. Pediram-lhe que elaborasse tal documento.

Informado sobre o documento a ser redigido, 0 Jornal do Brasil de 24 de maio entrevista o Professor, que salienta o papel da Faculdade de Direito da Universidade de São Paulo nos grandes movimentos políticos do Brasil.

O conselho da Ordem dos Advogados do Brasil, expressou "voto de homenagem" ao Professor Goffredo Telles Junior e outros "Por tudo que têm feito em favor da livre manifestação do pensamento e da Democracia".

No dia $10^{\circ}$ de junho de 1977 dirigiu carta ao Diretor da Faculdade de Direito da Universidade de São Paulo, formulando seu repúdio às violências perpetradas contra estudantes e contra o prédio da Faculdade pelos "agentes da desordem oficial".

Não se omitindo comodamente diante das crises estudantis ou políticas, Sua Excelência concede entrevista à "Visão" na qual condena as constantes violações da Constituição, denuncia os efeitos corruptores do chamado Estado de Exceção, e mostra o anseio nacional pelo Estado de Direito. No mesmo dia, fala no Centro de Atualização Cultural sobre a história e o espírito da Faculdade de Direito do Largo de São Francisco. No dia seguinte fala para a Rede Globo de Televisão sobre a volta do Brasil ao Estado de Direito. A 30 de julho, na sessão da Congregação dos Professores da Faculdade de Direito da Universidade de São Paulo, lê seu voto sobre a situação política do País, demonstrando que a Constituição do Brasil e o "pacote" das emendas de abril eram ilegais, inconstitucionais e ilegítimas.

Durante o mês de julho, elaborou o célebre documento solicitado em maio, cujo lançamento é anunciado pelo "Jornal da Tarde", como um manifesto de Professores de Direito sobre a situação nacional.

o Jornal do Brasil, de 2 de agosto, anuncia que 0 manifesto dos juristas estava concluído; que o autor lhe dera o nome de "Carta aos Brasileiros" e recebera cerca de cem assinaturas de vultos eminentes das letras jurídicas nacionais. 
Publicou a seguir entrevista com o autor, revelando, em síntese, as linhas mestras do documento.

Nos dias seguintes, o noticiário dos jornais de todo o País, sobre a Carta aos Brasileiros foi abundante. Numerosas entrevistas foram dadas à imprensa e outros órgãos de divulgação.

Antes mesmo de ser lançada, a Carta aos Brasileiros foi objeto de discursos no Parlamento Nacional e comparada com o "Manifesto dos Mineiros".

Finalmente, a 8 de agosto de 1977, às 8 e meia da noite, no pátio das Arcadas, no interior da Faculdade de Direito do Largo de São Francisco, frente ao monumento dedicado aos estudantes mortos em 1932, na luta pela constitucionalização do País, e perante uma multidão emocionada, Professor Goffredo leu a Carta aos Brasileiros.

No dia seguinte e subseqüentes, o documento de 14 páginas datilografadas foi publicado na íntegra, com grande destaque por toda imprensa nacional. Teve extraordinária repercussão em todo o País. Alcançou manchetes de primeira página nos melhores jornais do mundo e foi traduzido para numerosos idiomas, em sua divulgação no exterior.

A "Carta aos Brasileiros" foi transcrita nos Anais do Parlamento Nacional, das Assembléias Legislativas de diversos Estados e de numerosas Câmaras Municipais. Recebeu a adesão de várias Seccionais da Ordem do Advogados do Brasil, da Associação dos Advogados de Săo Paulo e de muitas entidades representativas. Obteve a aprovação de vultos exponenciais da intelectualidade nacional. Uma imensa multidão de brasileiros the deu apoio incondicional.

Em setembro de 1977, o prof. Goffredo Telles Junior proferiu uma conferência de mais de duas horas, na sede da Comissão Nacional de Energia Nuclear, no Rio de Janeiro, sobre os acordos do Brasil com a Alemanha, a respeito da instalação de usinas nucleares no Brasil.

Em 8 de outubro de 1977, publicou, no "Jornal do Brasil", do Rio de Janeiro, o artigo "Um só gesto", que é uma rigorosa demonstração da ilegalidade, inconstitucionalidade e ilegitimidade da Constituição de 1969 e das leis de exceção do regime vigente, e que termina com um vigoroso apelo, dirigido ao Presidente da República, para que ele tenha a coragem de executar o gesto de implantação do Estado de Direito no Brasil.

o "Jornal de Brasília" do dia 26 de outubro publicou entrevista sua, de página inteira, sobre a situação política do 
Brasil e sobre a "Carta aos Brasileiros"; e, em 3 de novembro, transcreveu o artigo Um só Gesto.

Em novembro de 1977, os trezentos professores e pesquisadores dos vários países reunidos no 7. ${ }^{\circ}$ Encontro da Associação de Estudos Latino-Americanos (LASA), realizado na cidade de Houston, no Texas, Estados Unidos da América, aprovaram por unanimidade, uma resolução de apoio, solidariedade e saudação aos Professores da Faculdade de Direito da Universidade de São Paulo, que acabavam de pedir a volta ao Estado de Direito, e aos que, no Brasil, vinham lutando, corajosamente, contra as violações dos Direitos Humanos, da liberdade de expressão e de associação.

Em $10^{\circ}$ de fevereiro de 1978 , na sessão solene comemorativa do $35 .^{\circ}$ aniversário de fundação da Associação dos Advogados de São Paulo, pronunciou palestra sobre os conceitos de autoridade e de abuso de autoridade.

Em 13 de fevereiro, a Diretoria da Associação dos Advogados de São Paulo deliberou constituir uma Comissão Especial de sete juristas, "para análise da Constituição Brasileira, tendo em vista sua alteração, bem como da Legislação Complementar". O Prof. Goffredo foi incluído nessa Comissão.

Em princípios de março, o Conselho Federal da Ordem dos Advogados do Brasil o designou para Relator da tese " $O$ Estado de Sitio e as outras salvaguardas", a ser apresentada à VII Conferência Nacional da Ordem dos Advogados do Brasil.

No mês de abril, a Associação dos Advogados de São Paulo começou a distribuir um estudo sobre a Constituição do Brasil, de mais de cem páginas, elaborado pela já mencionada Comissão Especial dos sete juristas.

No dia 15 de abril de 1978, na solenidade comemorativa do $41 .^{\circ}$ aniversário da fundação do Sindicato dos Jornalistas Profissionais do Estado de São Paulo, proferiu, na qualidade de orador da noite, uma conferência sobre o tema "Imprensa $e$ Liberdade Democrática".

Teve atuação destacada na VII Conferência Nacional da Ordem dos Advogados do Brasil, realizada na cidade de Curitiba, Estado do Paraná, de 7 a 12 de maio de 1978. Sua tese "O estado de sítio e as outras salvaguardas" foi aprovada por aclamação. Mais de uma vez, também, nas suas intervenções por ocasião dos debates de outras teses, foi aplaudido de pé. Sua tese se acha publicada nos Anais da Conferência.

Em 17 de agosto de 1978, seu nome foi apresentado, em documento assinado por numerosos parlamentares, à direção 
do MDB (Movimento Democrático Brasileiro), para ser candidato desse Partido a Vice-Presidente da República, na chapa encabeçada pelo General Euler Bentes Monteiro.

$\mathrm{Na}$ noite de 23 de agosto, durante a Convenção Nacional d.o MDB, retirou sua candidatura à Vice-Presidência da República, em favor do Senador Paulo Brossard.

\section{Bibliografia}

Quase toda, a obra de Goffredo Telles Junior versa Direito Político e Constitucional, Filosofia e Filosofia do Direito. Seus trabalhos exprimem sempre a incontestável inspiracão democrática, alicerçada no estudo e pesquisa dos princípios científicos que legitimam Constituições e Leis.

Júnior.

Publica-se a seguir a bibliografia de Goffredo Telles

\section{Livros}

O Direito Quantico, Ensaio sobre o fundamento da ordem jurídica, 5. ${ }^{2}$ ed., revista e aumentada, ed. Max Limonad, São Paulo, 1980 (1. a ed. em 1971, Max Limonad).

A Criação do Direito, 2 v., São Paulo, 1953.

Filosofia do Direito, 2 v., ed. Max Limonad, São Paulo, 1965.

Tratado da Consequencia, Curso de Lógica Formal, 5. ${ }^{\circledR}$ ed., José Bushatsky, São Paulo, 1980.

A Democracia e o Brasil, ed. Revista dos Tribunais, São Paulo, 1965.

Justiça e Juri no Estado Moderno, São Paulo, 1938.

A Definição do Direito, São Paulo, 1941.

2. Ensaios

O Sistema Brasileiro de Discriminação de Rendas, Assembléia Nacional Constituinte, Anais, também publicado em plaquetas, ed. Imprensa Nacional, Rio de Janeiro, 1946.

O Estado de Sitio e as outras Salvaguardas, tese apresentada à vir Conferência Nacional da Ordem dos Advogados do Brasil, maio de 1978, Curitiba, publicada nos Anais da Conferência.

Resistência Violenta aos Governos Injustos, na "Revista da Faculdade de Direito", ano L, de 1955, também publicado em plaquetas.

Lineamentos de uma Constituição Realista para o Brasil, na "Revista da Faculdade de Direito", ano LIV, fascículo II, de 1959, também publicado em plaquetas.

Lineamentos de uma Democracia Autêntica para o Brasil, na "Revista da Faculdade de Direito", ano LviII, de 1963, também publicado em plaquetas.

Que são, afinal, os Direitos Humanos?, na "Revista do Advogado", n. 3, dezembro de 1980, órgão da Associação dos Advogados de São Paulo. 
Revisão dos Conceitos de Autoridade, Autorização, Permissão, Direito Subjetivo e Norma Juridica, na "Revista da Faculdade de Direito", v. LXXII, 1. fascículo, de 1977, também publicado em plaquetas.

A Reforma da Universidade, Instituto Brasileiro de Estudos Políticos, São Paulo, também publicado em plaquetas, 1968.

Dissertação sobre o Universo, na Revista da Faculdade de Direito, ano Lv, 1960, também publicado em plaquetas.

A Reforma da Universidade, Instituto Brasileiro de Estudos Políticos, Săo Paulo, também publicado em plaquetas, 1968.

Dissertação sobre o Universo, na Revista da Faculdade de Direito, ano LV, 1960, também publicado em plaquetas.

Nota à Margem da "Dialética do Conhecimento", tese apresentada ao III Congresso Nacional de Filosofia, Anais, São Paulo, 1959, também publicado em plaquetas.

$O$ Mor $\boldsymbol{e} o$ JE, tese apresentada ao III Congresso Nacional de Filosofia, São Paulo, 1959, Anais, também publicado em plaquetas.

Spencer Vampré, Edições da Academia Paulista de Letras, 1964 (plaqueta).

História Natural do Direito, para o volume "Estudios", em homenagem a Luiz Recaséns Siches, a ser editado pela Universidade Autônoma do México.

3. Trabalhos para a Enciclopédia Saraiva do Direito (verbetes).

Norma jurídica (37 páginas).

Lei (Teoria da lei) ( 7 páginas).

Direito Subjetivo (39 páginas).

Coação - Coatividade (28 páginas).

Autoridade - Autorizaçāo - Autorizar (37 páginas).

Autorizante (26 páginas).

Autorizamento (3 páginas).

Absoluto (26 páginas).

\section{Cadernos de Estudo}

Oito cadernos para o curso de Introdução ao Estudo do Direito, edição mimeografada, publicados pelo Centro Acadêmico XI de Agosto, 1980.

\section{Pronunciamentos}

Carta aos Brasileiros, Proclamaçāo de Princípios, ao ensejo do Sesquicentenário dos Cursos Jurídicos no Brasil, São Paulo, 1977, publicada pela imprensa nacional e estrangeira, e na "Revista da Faculdade de Direito", v. LXXII, 2. ${ }^{\circ}$ fascículo, de 1977.

Pronunciamento, Proclamação de Princípios, feito na Congregação dos Professores da Faculdade de Direito, publicado na "Revista" dessa Faculdade, ano LXIII, de 1968.

\section{Artigos Principais}

Revisão dos Conceitos de Autoridade, Autorização, Permissão, Direito Subjetivo e Norma Jurídica, "Revista da Faculdade de Direito", USP, v. LxxII, 1.0 f., 1977 . 
Que são, afinal, os Direitos Humanos?, Revista do Advogado, n. 3, dez. 1980, órgão da Associação dos Advogados de São Paulo.

Resistência Violenta aOs Governos Injustos, I, II e III, O Estado de S. Paulo, 29 e 30 de junho e 6 de julho de 1955 .

O Direito Quântico, Revista Brasileira de Filosofia, $4 .^{\circ}$ trimestre de 1970.

$O$ Direito Quântico (novo artigo com o mesmo título do anterior), Revista da Faculdade de Direito, USP, v. LxviII, 1. ${ }^{\circ} \mathrm{f} ., 1973$.

Discriminação Constitucional das Fontes de Receita Tributária, Revista de Direito Público, V. 4, 1968, São Paulo.

Por uma nova Constituição, I, II e III, O Estado de S. Paulo, 21 e 28 de agosto e 4 de setembro de 1966 .

Um Poder Legislativo Autêntico, Revista de Direito Público, V. 14, 1970.

Um Poder Legislativo Autêntico, I, II e III, Diário de S. Paulo, 26 de novembro, 3 e 10 de dezembro de 1970.

O Poder Legislativo: Definição da Democracia, Folha de S. Paulo, 29.04.1969.

O Poder Legislativo: Abismo entre Povo e Parlamento, Folha de S. Paulo, 06.05.1969.

O Poder Legislativo: Instituições Representativas, Folha de S. Paulo, 13.05.1969.

O Poder Legislativo: O Departamento Legislativo, Folha de S. Paulo, 20.05.1969.

O Poder Legislativo: Câmara dos Deputados ou Assembléia Nacional, Folha de S. Paulo, 27.05.1969.

Falsificação do Brasil, Folha de S. Paulo, 03.06.1969.

Mito e Medo, Folha de S. Paulo, 10.06.1969.

A eleição do Presidente da República, Folha de S. Paulo, 19.06.1969.

Formação de Legisladores, Folha de S. Paulo, 24.06.1969.

Escola de Legisladores, Folha de S. Paulo, 28.06.1969.

Em Sintese, Folha de S. Paulo, 08.06.1969.

A Doutrina da Segurança Nacional, O Estado de S. Paulo, 12.11.1978.

Depoimento sobre as Reformas Constitucionais feitas pelo Governo, O Estado de S. Paulo, 21.09.1978.

Um Só Gesto, Jornal do Brasil, 08.10.1977; Jornal de Brasília, 03.11.1977. Reforma da Universidade, I e II, Folha de S. Paulo, 3 e 6 de junho de 1968.

A Carreira Docente na USP, O Estado de S. Paulo, 21.10.1973; Revista Brasileira de Filosofia, f. 92, v. 23, 1974.

Preleção sobre o Justo, Justitia, órgão do Ministério Público de São Paulo, v. $50,1965$.

Preleção sobre o Valor, Justitia, v. 53, 1966.

Ruy Barbosa, o Sonhador da República, Letras e Artes, suplemento dominical do jornal A Manhã, Rio de Janeiro, 12.11.1949.

Spencer Vampré, Revista da Faculdade de Direito, USP, 1965.

Concepção Sintética do Direito (apanhado do pensamento de Spencer Vampré), Revista da Faculdade de Direito, USP, v. XXXVII, 1942. 


\section{Entrevistas Principais}

A Gazeta, 30.10.59, sobre a reforma constitucional.

A Gazeta, 30.04.68, sobre a reforma da Universidade.

Diário de S. Paulo, 05.05.68, sobre a reforma da Universidade.

Diária da Noite, 06.05.68, sobre a reforma da Universidade.

Jornal do Brasil, 15.02.76, sobre um discurso do General Rodrigo Otávio, na reabertura dos trabalhos do Superior Tribunal Eleitoral.

Jornal do Brasil, 10.03.76, sobre o Poder Moderador.

Folha de S. Paulo, 11.08.76, sobre a data de 11 de agosto.

o Estado de S. Paulo, 11.08.76, sobre o mesmo assunto.

Jornal da Tarde, 03.03.77, sobre a prova de redação nos exames vestibulares.

Jornal do Brasil, 22, 23 e 24 de abril de 1977, sobre os regimes de exceção e a Democracia.

Aqui, São Paulo (semanário), 11.05.77, sobre "O que os estudantes querem".

Visão (revista), 06.06.77, sobre o Estado de Exceção e o Estado de Direito.

Visão, 01.08.77, sobre o idealismo revolucionário da Academia do Largo de São Francisco.

Jornal do Brasil, 02.08.77, sobre as linhas mestras da "Carta aos Brasileiros".

Folha de S. Paulo, 07.08.77, sobre antecedentes, elaboração e sentido da "Carta aos Brasileiros".

Folha de S. Paulo, 11.08.77, sobre o papel da Faculdade de Direito nos grandes acontecimentos da História Brasileira.

O Globo, 30.09.77, sobre uma entrevista do Ministro Nascimento e Silva, da Previdência Social, a respeito da incorporação da democracia social à democracia política.

Jornal de Brasília, 26.10.77, sobre a "Carta aos Brasileiros" e a situação política do Brasil.

Cinco de Março, jornal de Goiânia, 19.12.77, sobre a situação política nacional.

Jornal do Brasil, 01.03.78, sobre a revisão da Constituição pela Comissão Especial da Associação dos Advogados de São Paulo.

Folha de S. Paulo, 02.03.78, sobre o mesmo assunto.

O Globo, 19.03.78, sobre as salvaguardas propostas pelo Governo.

Folha de S. Paulo, 02.04.78, sobre as propostas constitucionais, apresentadas pela Associação dos Advogados de São. Paulo.

O Globo, 03.04.78, sobre o mesmo assunto.

Folha de S. Paulo, 06.05.78, sobre as reformas preconizadas pelo Governo.

Isto é (revista), 17.05.78, sobre a "Carta aos Brasileiros" e sobre a natureza do moderno Estado de Direito ou Estado de Justiça.

o Globo, 17.06.78, sobre as medidas preconizadas pelo Governo: Conselho Constitucional, estado de emergência e medidas de emergência

Jornal da Tarde, 26.06.78, sobre o mesmo assunto e a necessária convocação da Constituinte

0 Globo, 27.06.78, sobre o mesmo assunto.

Última Hora, 11.08.78, sobre a missão política da Faculdade de Direito. 
Isto é (revista), 16.08.78, sobre o significado histórico da "Carta aos Brasileiros".

Jornal do Brasil, 11.09.78, sobre as reformas preconizadas pelo Governo e sugestões.

O Estado de S. Paulo, 21.09.78, sobre o mesmo assunto.

O Globo, 30.09.78, sobre a inconstitucionalidade do decreto antigreve (Dec. Lei n. 1.632).

Jornal do Brasil, 01.10.78, sobre o mesmo assunto.

O Globo, 07.10.78, sobre o Colégio Eleitoral do Presidente da República.

O Globo, 29.11.78, sobre a nova Lei de Segurança Nacional.

\section{Trabalhos Parlamentares}

Na Assembléia Nacional Constituinte de 1946 e na Câmara dos Deputados (1946 a 1950) - Discursos principais:

Discursos principais:

Resposta a Luiz Carlos Prestes

Contra a Emenda Totalitária n. 3.159 e pela Democracia.

Por um Sistema Racional de Discriminação de Rendas.

Em Defesa dos Municípios Brasileiros.

O Problema do Algodão.

O Problema do Fio de Seda.

O Problema da Brucelose.

Contra o Instituto Internacional da Hiléia Amazônica.

Em Defesa dos Minérios e das Areias Monazíticas do Brasil.

Pela Incorporação dos Abonos aos Salários dos Trabalhadores.

A Polícia Militar (apresentação de um substitutivo, com longa justificação, ao Projeto que reorganizava a Polícia Militar). 